\title{
Economic Participation Through the Micro Credit Scheme: Transforming Poor Women or A Case of 'No Leave, No Transfer'
}

\author{
Nwanesi Peter Karubi \\ Faculty of Social Sciences University Malaysia Sarawak
}

\begin{abstract}
The subject of this paper is to critically evaluate some of the fundamental issues relating to the application of micro credit and its transformation of gender roles and gender equality, especially in a developing society like Nigeria. In sum, this article critically examines the relationship between the micro credit scheme and women's economic empowerment. It probes how such economic empowerment (if any), influence or impact on traditional views on women's place in the family.
\end{abstract}

Keywords: Micro credit, Economic empowerment, Economic participation, Gender equality, Gender roles, Market women

\section{Introduction}

Micro credit scheme and women's economic empowerment have been widely explored by many researchers, too numerous to cover in this article. The focus in this article, therefore, is to critically examine the utilization of the micro credit scheme by market women in two Nigeria states and its contribution to the recipients' socioeconomic empowerment. This is because in many instances, human beings do not react directly to events; they act based on their interpretation of the meaning of events (Wallace 2008, 65). Hence, the extent development programs and policies have enhanced gender equality or empowerment have remained a thorn on the advocates of micro credit (MC) scheme. Often, advocates of MC repeatedly present a make-believe presumption that the scheme is a 'magic bullet', a one size fits all or a solution to the feminization of poverty in the developing nations. To drum the above presumption, the 2005 UN Millennium Project identifies micro-credit as "one of the development strategies... that should be implemented and supported to attain the bold ambition of reducing world poverty by half" (UNCDF 2005, 5). Not surprisingly the United Nations designated 2005 as the International Year of Micro-credit. Thus, many women in the developing countries are enjoined to participate in micro credit/financing programs, because most women development proponents and academic scholars associate micro credit/financing scheme with women's empowerment $t^{\mathrm{ii}}$. This is without merit, but often over-generalised. Opinion on the impact of micro credit by those who views it as a magic bullet or a cure-all panacea for development dominate development discourse. For example, Roxin et al $(2010,34)$ asserts, "regarding the influence of micro credit on economic, social and political empowerment, our findings suggest that micro credit has a substantial impact on women's economic empowerment". Also, according to Michael Strong, CEO \& Chief Visionary Officer of an NGO known as 'FLOW': "Today, tens of millions of women around the world have greater economic independence and self-worth as a consequence of microfinance projects".

Other works by the acclaimed economist Prof. Muhammad Yunus holds similar views. In sum, Yunus noted; "giving the woman control of the purse-string was the first step in giving her rights as a human being within the family unit" $(2003,88)$. In fact the transformation niche of MC is captured in the 2005 UN Millennium Development Goals document. It states, "because of the interconnection of financial power, poverty and women, microcredit has an active role in improving economic equality. Increased economic power enables women to improve other areas of their - and their children's - lives" $(2005,5)$.

Certainly, the $21^{\text {st }}$ century has witnessed differing dynamics in pursuit of gender egalitarianism on political and socioeconomic relations. However, in many societies and communities, these efforts seem more of rhetoric and sometimes myth rather than a reality. It often raises some fundamental questions, such as, whether the roles of many NGOs/GOs that championed these grounds are a mere gimmick to attract sympathy or financial gains rather than the well-being of the needy. For instance, despite the widespread linkage of micro credit to women's empowerment, gendered roles have remained rigid in most developing nations. These roles are even more exigent as many women embrace work outside their homes. Deepa et al $(2000,15)$ summed this rigidity ${ }^{\mathrm{iii}}$ with this quote from an old Uganda woman;

Women can do all the work, except to propose marriage. Nature does not allow women to marry men, just like nature does not allow men to wash dishes, cook, and sweep. People will lose confidence in a man and his wife if they find him in the kitchen. -Older woman, Uganda 1998.

Besides, it has not been empirically established that the 'magic bullet status' (see Fig 1) liken of the 
micro credit/finance scheme is realistic. Unfortunately, the nature of this assumption appeared to substantiate the homogeneity of women. Yet it is obvious, grouping women as homogenous either in nature or disposition is a pure socio-scientific fallacy. The position taken in this article is that development programmes and policies of any institution, provide diverse possibilities rather than a fixed set of conclusion. This article seeks to critically examine empirical data on the impact of micro credit in respect to its transformation of gender roles and gender equality within the family.

\section{The Market Women Of Nigeria}

Traditionally, women and men's sphere of activities were rather complementary, although this does not necessarily imply equality between the sexes because gender roles are enshrined in many of the world cultures and norms. The degree of the inequality between the sexes differs from nation to nation, groups, social classes and more importantly, historical eras. Nevertheless, within the traditional economic systems, both women and men shared responsibilities for the sustenance of their families. In Nigeria, women have always engaged in work both within and outside their homes. Their economic activities are seen as very crucial to the internal distributive trade system (see Nnaemeka 1998) as well as in the processes of agricultural produce for raw materials or food. Many of the women in such trade are identified as market women.

Market women in Nigeria (or those in other West African nations) are predominantly subsistence traders. They are small scale entrepreneurs. Their commodities include foodstuff, craft, hair products, clothes and other essentials. Some of these commodities are either produced in their homes or purchased directly from producers or middlemen. Most market women in Nigeria dwell in the cities, semi-urban, or the rural areas. Aidoo (cited in Nnaemeka 1998, 45) wrote;

There are more than two hundred million women in Africa involved in different economic activities, but one group of women almost entirely peculiar to West Africa is that of the market women (see also Ayittey 2005, 31).

According to Aidoo, "these women's economic activities have a strong bearing on the general survival and sustainability of the West African region and Nigeria in particular." Nnaemeka notes;

It is through market women that supplies are distributed or sold to a large percentage of the population in most metropolitan or rural areas. Market women offer varieties of products and services: vegetables, meat, poultry, fish, spices, cooked foods, baskets, clothes, shoes, cheap jewellery, tailoring, sewing, and hairdressing. They live in the cities as well as in villages in Nigeria and in other West African towns and rural communities $(1998,45)$.

Unfortunately, this economic activity of market women does not translate into gender equality, especially at the family level. In reality, decision-making and roles are rigidly gendered. Male by tradition are fundamentally viewed as the head of the family, and female the neck ${ }^{\text {iv }}$ of the family. A reflection of the fact that while men 'take charge'; women 'take care'.

In the past, market women were mostly the less educated, but in recent times the occupation has attracted those with better education or skills. This is as a result of high unemployment, large family size and to financially support their family members. Most market women lack adequate capital base to kick-start their small enterprises. Some writers attribute this to lack of access to land, limited resources, unfavourable inheritance laws, informal social practices, norms or lack of savings (see Boserup 1970; UN Habitat, 2006). To overcome these shortcomings, many ${ }^{v}$ market women in southern Nigeria use funds provided by the micro credit scheme to kick-start their micro enterprises.

As noted above, in the last two decades, micro credit or its advanced edition (micro financing) is increasingly being promoted as a 'magic bullet', 'one-size-fits-all' or a 'cure-all panacea' for development. This promotion of $\mathrm{MC}$ as a cure-all panacea by many in the development community has triggered an explosion of micro credit (MC) organisations mushrooming in developing countries. Kabeer (2005) notes that at the same time, however, this evangelism of this scheme appears to have triggered a dismissal of micro finance, which is often as sweeping as poorly grounded in evidence as the claims themselves. The strong linkage of MC to empowerment, is based on the understanding that empowerment is spiral in nature rather than a linear process. Affirmatively, empowerment is a non-linear, multi-dimensional process evolving along different pathways material, perceptual, cognitive and relational (See Molyneux 1985; Nwanesi 2008; Roxin et al 2010), but it is not empirically possible to conclude that all development paradigms of MC will automatically lead to women's empowerment.

\section{Methodology}

Qualitative method was employed to obtain an in-depth and quality data. The method is certainly more suitable for this study as it provides richer meaning to respondents' data than quantified information. Furthermore, it enables the researcher to assess the degree of change in attitudes, values and norms governing the traditional family roles among the Yoruba and Ibo ethnic groups of Nigeria. This assessment is in the context 
of economic participation through the use of MC. As noted, qualitative data can be richer in meaning than quantified data. This is implicit in the cliché (Babbie 2010,24). Using this method ensures both observation and interviews were fully harnessed to achieve quality data. Both tools assist the researcher to harmonize spoken and unspoken data from the respondents.

Gender analysis is used in this study to evaluate the impact of micro credit schemes of gender issues at the family level. It questions the dominant conclusion that the micro credit programme is a transformer of traditional behaviours and practices. This is because gender analysis states that the character people take on as a man or woman, and the actions associated with these characters are usually socially constructed, instituted or internalized (see Pilcher \& Whelehan 2004). By adopting gender analysis, this study explores the degree of effectiveness of micro credit schemes in dismantling an internalized cultural norm, that strongly favours male superiority over their female counterpart.

This research respondents are market women and MC participants. To ascertain the contributions and level of MC input to women's economic empowerment the study focused on those that have been with MC for 2 years or more. Most participants were selected from those in their second or higher loan cycle on the programme. The choice for this period is to assess the impact of the scheme in relation to their roles and decision making ability within their families. It is understandable that the impact is very hard to measure when the period of participation in the programme is too short to identify the effects of empowerment processes. To draw a representative sample from this population, selection criteria were based on respondents' location, age, the nature of trade, and marital status. With regard to the various characteristics of the respondents, different variables were considered to assure a valid impact measurement.

The study was conducted in two major cities in Southern Nigeria-Ibadan (Oyo State) and Owerri (Imo State). Both cities have large markets, with over 50percent of their stalls owned and operated by women. As administrative capitals of Oyo and Imo States, Ibadan and Owerri have a constant flow of goods from both the rural and urban areas. The ethnic backgrounds of the interviewees were Yoruba and Igbo. The women from these ethnic groups are renowned for their industriousness and involvement in small and micro entrepreneurship $^{\text {vi }}$. The respondents' age ranged from 24 to 60 years. In all, 25 respondents were interviewed. The 25 respondents are micro credit loans' recipients. With the exception of two respondents used here as case studies, each woman was interviewed for a period lasting between 45 minutes and 1 hour and 25 minutes. The two women selected as case studies were chosen because their accounts were vivid. They were interviewed on more than one occasion. In addition, these two participants consented when the researcher requested to be allowed to experience their lifestyle for at least a day. This participant-observation provided an in-depth overview of their daily lifestyle.

Information that may reveal the identities of respondents has been deliberately concealed. Respondents were given pseudonyms. This is because;

Researchers have a duty to ensure that no harm comes to their subject... as a result of their agreement to participate in the research. If we cannot guarantee that such participation may improve their lives, we must ensure, at least, that our scrutiny of them, does not leave them worse off (Melrose 2002, 23).

Data on capital, earnings and the total amount borrowed from MC outfits were difficult to obtain. Most respondents were reluctant to share this information, and merely provided a passing estimate or statement on them. The researcher did not pursue it vigorously as it doing so would have contravened research ethics.

\section{Discussing Women's Development And Micro Credit Scheme}

The concept of development is often contentious given the widely divergent development levels and views within regions and scholars. Essentially, development connotes a process through the active participation of the people in their own concentration as they see them, relying primarily on their own resources and carried out under their control. That is to say less dependent on external handouts. Wolfgang paraphrasing Estave notes; It is much more than economic growth, which is merely a means; it is a total commitment to human well-being and it leaves no section of the human population outside the scope of change and development (Wolfgang 1992, 16).

Many writers uphold that since the United Nations First Development Decade in the 1960s, which initially emphasized welfarism and later the introduction of economic growth and the trickle-down approach, the development approaches have advanced considerably. Some authors argued that a major remarkable advancement of these approaches has been the move to consider gender equality as a key element of development ${ }^{\mathrm{vi}}$.

Women's concerns or gender issues were first integrated into the development agenda in the 1970s, and Women in Development (WID) championed it. However, Razavi and Miller $(1995,54)$ noted that;

Instead of approaching policy makers with a range of demands for women, WID advocates adopted a strategy of relevance. In other words, their demands for the allocation of development resources for women hinge on economic efficiency arguments about what women can contribute to the development process.

These two authors maintained; "The convergence of equity and efficiency concerns in this strand of 
WID thought has provided the basis for a powerful political strategy. It has also had a lasting impact on the way in which development planners think about women" (Razavi and Miller 1995). Indeed, enlisting women into economic activities is not the same thing as working to achieve gender equality and the empowerment of women. Abdo and Kerbage argued;

When women entrepreneurs are targeted, their loans are directed at the establishment of micro-enterprises concentrated in the service sector. Thus, these initiatives render women benefiting from micro-loans as own account workers who are considered by the ILO as vulnerable workers (ILO and Center of Arab Women for Training and Research 2009).

Yet this reality is at odds with the trend among microfinance providers to romanticize the informal sector, constructing it as 'the backbone of the economy'; and second, the prevailing assumption that providing micro-loans to micro-entrepreneurs will lead to their expansion and formalization.

Although micro-credit financing is considered as one of the most powerful tools for combating poverty, the sector still faces several serious problems. Many MC institutions usually charge excessively high interest rates to cover the high administrative costs of the micro-loans they offer to the poor people. This reality creates a tension between sustainability of the micro-credit sector and the outreach. On the part of the participants, the scheme has not been able to resolve many socio-cultural issues disempowering women.

Indeed, the 1995 Fourth World Conference on Women held in Beijing, provided a more structured framework for the world community to focus attention on areas of critical concern for women worldwide. The framework focused on two main areas. These include promotion of women's advancement and inequality in women's access to and participation in economic structures etc. Nonetheless, it is very vital to ask; how far-reaching these gender issues are. Often agencies, affirmed that giving women greater access to resources immensely contribute to an equitable and efficient development process (see Yunus 2003). However, sometimes this equally creates new problems while enlarging the older ones. There is no doubt that the development approach like micro financing schemes may have economically empowered ${ }^{\text {viii }}$ some women, however, there are many questions unanswered with its introduction.

Surely, proponents of efficiency approach literally assumed that most women in the developing nations have excessive free time that can be channeled into economic participation (see Diane 1992). Ironically, these women are overburdened with unpaid work without which family survival may be impossible. The same micro financing scheme provides the economic base for women, but it equally amplified their workload (see respondents' stories below). Obviously, with the increase in the number of micro credit participants, the welfare packages $^{\mathrm{ix}}$ provided by the states gradually dwindled or completely removed. What is more, social reforms such as gender equal participation in the household duties and decision-making are often viewed as a precise right from the male head of the family and a taboo to think otherwise.

Concisely, the micro credit scheme provides women with a soft loan to start a small business, but in many instances, increases their workload, health problems, financial liability and responsibilities. In the end, most women are trapped in the complicated neo-liberal socioeconomic policies of the IMF/World Bank. What is more, often assumptions are presented as factual. There is no doubt MC has its place in women's development paradigm but it cannot be assumed to be a magic bullet. Because even with its introduction, most African women that utilize the scheme are still rooted in the 'balancing act' that has remain the history of their life. As Nnaemeka in Cornwall (2005, 31), stressed;

African women's lives are a balancing act indeed. Fighting on all fronts to contend with external forces, bridge the fissures between public and private, link home and abroad, and maintain sanity through it all requires great strength and imagination. ... Africa women are '[fighting] against two colonialisms' - that is internally induced patriarchal structures and externally engineered imperialistic context.

Certainly, the tall-tale of the micro credit scheme has not solved the African women's quandary, at least for now (see Fig. 2).

Intrinsically, the focus on grassroots economic participation, which often takes the form of micro financing schemes or other participatory approaches that are advanced with efficiency nuance, has failed to address women issue but rather increase their responsibilities. Likewise, the common mainstream emphasis on economic growth and hypothetical gender equality, which permeated the whole field of development, has not only exempted fundamental issues in development but has also deepened the economic and socio-cultural status gap between women and men. As Wolfgang $(1992,18)$ noted, "the fact that development either leaves at the rear or in some ways amplify the level of poverty, stagnation, marginality and actual exclusion from social and economic progress, draws a considerable criticism". No wonder Kothari and Minogue $(2002,164)$ maintained that the idea of development "stands like a ruin in the intellectual landscape". These writers stressed that delusion and disappointment, failures and crime have been the steady companions of development, and they tell a common story - "it did not work" (see Afshar 1991). Indeed, many economics conventional approaches or policies leave out much of the work that women do at home and in the community.

Findings and Analysis: Nigerian Women's Life, Work and Family 
By virtue of their physiology, "woman" is the feminine component of the human species who, apart from serving as a vehicle for nurturing human life, is also a producer, a consumer and equally endowed agent for fostering wholesome political, social and economic development in the society (Obasanjo and Mabogunje 1991, 12).

The responsibilities that come with the biological function of 'givers and nurture' of life make women a peculiar force in overall national growth, survival and development. In Nigeria, the role of women varies from domestic chores to day-to-day financial or socio-cultural activities. What is more, part of female socialization is to be financially supportive and socio-culturally submissive to their spouses and families. To say the least, women's income and properties are viewed as families or husbands' wealth. A respondent tagged CP1 summed it in these few words;

In Nigerian, women are duty-bound to support their husbands in any way they could... 'Although, all fingers are not equal, every little contribution is an attribute of a woman's worth, to her husband and family ${ }^{\mathrm{x}}$.

The impression, however, is that women are [not] compelled to, as data from the field indicated. All respondents in this study maintained that they were neither forced nor compelled to assist their spouses, but such support is mutual. According to a respondent tagged CP2; "most families in Nigeria survive, because both spouses earn, especially when the woman of the house is not the sidon-de-look ${ }^{\mathrm{xi}}$ type". Using a common phrase among the Yorubas she adds, "When the shit hits the fan, you don't know whom it will touch, beside when two people urinate together, the foam is immense". Another coloured the logic in this way,

When two elephants fight, the grass suffers. I do not want my children to suffer because of our failure to play our roles. The truth of the matter is when the left hand washes right hand, the right hand in turn washes the left hand, that way both hands are clean. But that doesn't mean I am equally to my husband. He leads, I follow (CP 4).

According to the data, while they are not compelled to, women appear to shoulder more family responsibilities than their male counterparts. Despite the common notion that males are the breadwinners, their financial contribution to their families are often allocated to the so-called key household needs such as house, cars and furniture. These items are purchased periodically. Women, on the other hand, use their earnings for family's food, essentials, and children's needs such as pencils, pocket money, books, school's tolls and duties, community tolls and duties. This is apparent from the following response of one of the research subjects: "Once you depend on your husband for money to buy "salt and pepper, you and your children will go hungry and naked (MCP13)".

Data from the field indicate that the financial contributions of almost all of the respondents to their families have increased over the years as a result of their economic activities. This has been attributed to their involvement in economic activity, while reducing their spouses' financial responsibilities to the family. Broadly speaking, respondents often shoulder more financial liability for their respective families. These include taking charge of the family essential needs which could range from food, clothing to paying the house rents. In addition, they are solely responsible for the repayment of their MC loans and the interest rates. Two respondents address the issue in this way;

Well, we have to pay back our loans... Our husbands do their best and we do our best... what is the use of money if you cannot use it to take care of your family's needs. But to be honest, it's not an easy task, the family needs, our needs and the loans. But we must continue the struggle. A wife's life is tied to her husband and her children, without them her work is meaningless (CP19).

Another adds;

From the look of things, the loan is very helpful to start this business, but paying back the loan, the interest and supporting my family from the proceeds is back breaking. And since I started this business, if I ask my husband for money his response is what do you use your earnings to do. Sometimes, he will suggest I stop the trade completely if it's not working well... but how can I stop, money doesn't grow on trees or the roof of my house. All I ever ask of him is a little contribution, but he always assumes that make a lot of money. But where is the money... I spent it, on the family (MPC9). 


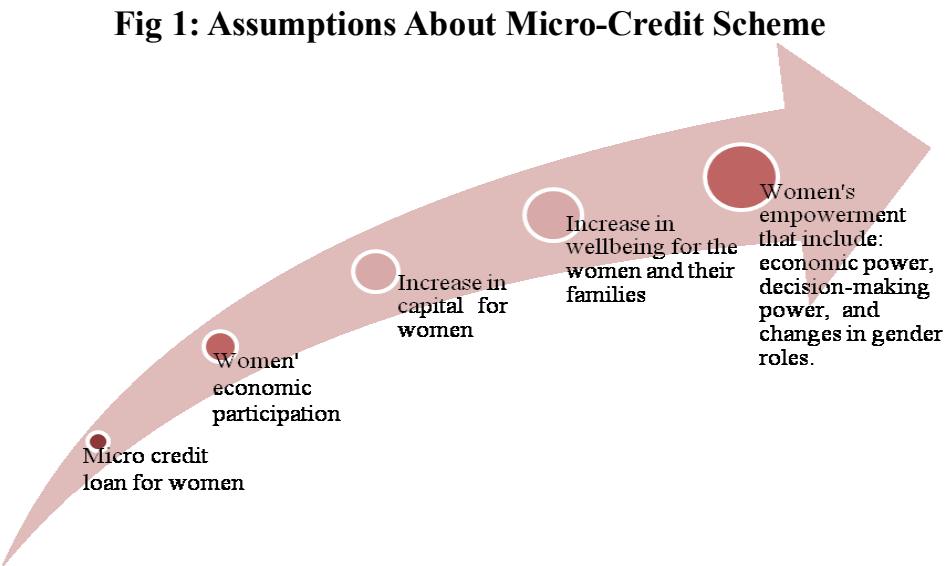

Early perception on women's involvement in MC loan. It stipulates that MC will automatically propel women into economic participation. Hence, economic participation will lead to increase in their capital. This will eventually culminate into women's empowerment.

Fig 2: The reality of Micro-Credit Scheme in the Southern Nigeria: No leave No Transfer

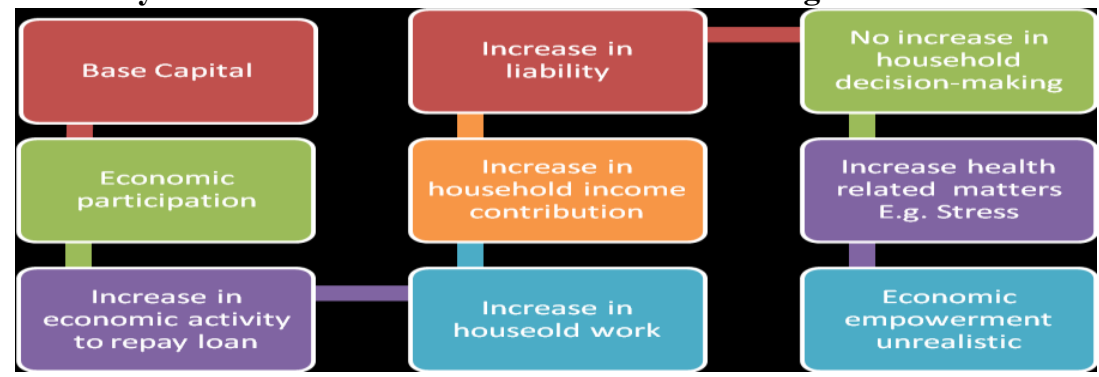

Although, the findings of this study show MC lead to women's economic participation, it established that the end product of MC is not economic empowerment. But increase in women's liability, house work, stress and little or no change in the level of decision making.

\subsection{Work and Family: 'No Vacation and No Retirement'}

Traditionally, African women have been the invisible working force. They actively strive with gladness in their hearts ${ }^{\mathrm{xii}}$ to ensure that their families have food on the table, and children are clothed, educated and sheltered. One way in which they have strived to guarantee the above process is through "buying and selling,xiii. In Nigeria, for example, a day in a market woman's life does not simply begin and end with buying or selling goods, it is interwoven with the daily existence and well-being of her family (directly) and with her community (indirectly). In sum, within a day, she is a mother, homemaker, financial provider (supporter), teacher, baby sitters; good neighbour, a cook and a partner. Simply put it this way, she is a superwoman and everywhere at the same time.

A good illustration of this superwoman is a respondent tagged 'CP11'. Her profile reads: 29 years at the time of interview, married at the age 20 with only primary school certificate as the highest educational attainment, she has three children (may have 1 or 2 more in the future), a Muslim, ethnicity-Yoruba, and lives in the Ibadan - city. She summed her position as follows;

I cook for my family at every given meal. In my culture, it's a woman's place to cook, clean my house and equally attend to the basic needs of the children, husband, and in-laws. Sometimes my husband helps, especially when I am pregnant or sick. But it is never the place of woman to demand her husband to perform domestic chores. Otherwise, the community, your family (extended family members) would tag you a bad-woman.

CP11's day starts from 5 am, with the Morning Prayer. Then she moves to sweep and clean her house and its surroundings. While she is at it, she cooks breakfast for her family and prepares her first and second children for school. As the day breaks, she feeds her third child and sets the breakfast table for her husband and the rest of her children. While her husband eats with the children, she goes to take a bath and get ready for her market activities. She is often the last to leave the breakfast table and the house in the morning because she has to wash and tidy up her home before leaving with her youngest child for her shop.

Because she lives quite a distance from the Bodaji - market, the respondent uses public transportation (or danfo bus ${ }^{\text {xiv }}$ ) back and forth between her shop and home. According to her, using public transportation in Ibadan can be "harder than giving birth"- her accounts of the bus stop: 
If you are too early, an angry crowd confronts you and if you are too late, you may never get to your shop until noon. At the bus stop, there is no queue or any form of organization; people are merely interested in reaching their destination. The bus operators often use this period to increase the bus fare and no one questions it. I guess I have no choice, because if I can't get to the market, my children may go hungry. Worst of all, I'll be loaded with debt. I have to pay part of my loan weekly.

When she eventually arrives at the market, she opens her shop, proceeds to clean, sweep or mop the floor and finally arranges her wares. According to CP11, "I usually seek out the fresh food stuff and make sure it is still in good condition before sampling them for customers". Even though most of her wares are dry foods, she still has to store them carefully away from the raindrops (the roof of her stall leaks when it rains) and filthy places. Procuring of goods for her daily trading is done every fortnightly or weekly depending on the market demands. She often goes to the wholesale market (a section of the Bodaji market ${ }^{\mathrm{xv}}$ ) often owned by men or older women. On such occasion, she endeavours to be at the market earlier than her usual days. This is to enable her to purchase the choicest products for her store and to equally gain ample time to carry out her morning routine in her store. Thus, from 8:30 am each morning, she attends to customers and as the afternoon approaches, her two older children join her and assist in any way they could. This practice of having the children in the market place solves the problem of day-care and provides some form of assistance. As respondent CP11 pointed out..." as a child and student, I (and other market women's children) took the market as our second home; our homework, changing clothes and lunch is either kept, eaten or performed here". That way the respondent and many other market women look after their children and manage their trading activities during the day. It is in the market that they have their lunch and even do their homework. The market is like a second home for most market women and their children.

As the evening approaches, she rushes out to purchase basic needs of her family and home. During the fieldwork, this researcher observed the urgency in her movement and activities. Her entire activities were framed into a mechanized like configuration. She was in and out of her store. She was simultaneously selling goods to customers, directing her children, and procuring family needs. Astonishingly, she was quite on time, and diligently worked with no traces of anger or frustration with her role as a mother and provider for her family. She was mentally prepared for "the rush hour" as they called it. I observed that, this rush hour might stretch from $4 \mathrm{pm}$ to $6 \mathrm{pm}$ or beyond. It all depends on the number of customers in a particular evening.

At the end of the day, respondent CP11 has to rearrange her wares for safekeeping, store them for preservation and finally lock up her shop. Around $6: 15 \mathrm{pm}$, she is ready to have another tedious bus experience, and this time with her children clinging to her sides for protection and guidance. At home, she attends to domestic chores such as cooking dinner ${ }^{\mathrm{xvi}}$, collecting water from the resident's ${ }^{\mathrm{xvi}}$ tap and other numerous tasks, although some of them are on a weekly basis. These include washing clothes and scrubbing floors (mainly on weekends). Although, sometimes her oldest son assists her in carrying out some of the less tedious tasks; his tasks include collecting water, washing dishes, arranging his and brothers' clothes etc. In addition, the respondent participates in market meetings. She attends community meetings (every fortnight), visits and takes care of her parents when they are sick. She equally takes part in other family or friends' functions such as wedding, naming or funeral ceremonies. Besides, it is her duty to attend and care for her children or husband when they are sick or injured. Some of these functions may compel the participant to neglect or completely stay away from her economic activities for a day or more. Ironically, paying her MC debt would not wait or be neglected.

Following the evening meals, the CP11 will finally check and calculate her day's earnings and pays some attention to her children's homework. Often, she goes to bed between $9 \mathrm{pm}$ and $11 \mathrm{pm}$. Nonetheless, she still attends to her household needs in the middle of the night if the necessity arises at such an hour. Her duty and commitment to her family is a twenty-four hours a day, seven days a week, and 365 days a year. As mentioned above and echoed by many market women; "there is no leave and no transfer for family commitment, it is, until death put us apart". The husbands' role is often the opposite of the above story. According to the respondent, the roles of married men in Nigeria are simple. She summarizes these roles as follows:

They are tagged bread winners of the family. They make their wives pregnant. But never lift a finger on house chores. Husbands complain about almost everything. These ranges from food not properly cooked, late dinner, dirty house, dirty clothes, children crying or making noise because he is watching TV or on the phone.

Unfortunately, the empowerment that $\mathrm{MC}$ promotes appeared to be unfeasible with this respondent and many others in this category.

The above narrative and quotes depict the life of a woman tagged CP11. As mentioned above, she uses the micro credit loan to ensure the continuity of her economic activities. Her activity is a reflection of an everyday story of many market women in Nigeria. Yet it will be wrong or out of context to hold, this is the life model of every market woman in Nigeria. Although some aspects can be generalized, others are common to a particular group. Nevertheless, it is safer to assume that each market women's family is unique in some ways. Take for instance the story of respondent MCP14, aged between 51 and 60 years. The Nigerian civil war of 
1966 to 1970 disrupted her training as a nurse, and she was finally discouraged from continuing her study after the war by her husband. This respondent lives in a village about 45 minutes by bus to Imo state capital-Owerri ${ }^{\text {xiii }}$. She owns and operates a shop in Owerri's central market.

MCP14 is a widow with nine children, a Christian, Ibo, and she sells various women's hair products. She uses the micro credit loans to ensure the continuity of her economic activities. According to MCP14, her day starts from $5 \mathrm{am}$, with a little prayer. As a practicing Catholic, she goes to church every morning from 5:15 am to $7 \mathrm{am}$. After the religious devotion, she leaves her home between 7:30 am and $8 \mathrm{am}$. On days she needs to travel to Aba, a neighbouring city, but in a different state of the federation, she leaves her home before $6 \mathrm{am}$. Such travel is vital to restock her store. On such days, morning church devotions are cancelled.

As the head of her family, and with grown up daughters, her female children perform most of the domestic duties ${ }^{\text {xix }}$. Occasionally, she cooks for the family and carry out the few domestic chores which her daughters neglected or ignored. Most mornings, before she arrives at her shop, her children would have opened, swept and arranged her shop and wares for the day's business before heading to their various schools. However, every day's issue or affairs relating to her family are tabled before her. Family welfare, finance, education, health and other related incidents are part of her everyday obligations. From an outsider's point of view, she makes the decision and equally ensures that her children are in line with the norms, customs and religious requirements of her community. As she puts it, "I have to act like the 'hen', protecting my brood from hawks; otherwise my in-laws will call them the children of a wayward mother ${ }^{\mathrm{xx}}$." However, some important decisions have to be approved by the most senior member of her extended family - that is her late husband's brother. According to her; "After all, I am still married to my husband's family and will do my best to abide by their advice"

Her shop is her base. She manages every aspect of the trade until 2 or $4 \mathrm{pm}$. Then, one or two of her children would join her at the market. The market officially closes around $6: 30 \mathrm{pm}$. At home, she attends to complaints, demands, negotiations with neighbours, family members and children. Before she goes to bed around 9:30/10 pm she ensures her children's whereabouts are known and there is enough food at home. Besides the above, her other responsibilities include spending (approximately) three months with any of her two daughters when they birth to new babies. This is a traditional obligation. As such she cannot refuse to go. During this period, she is expected to nurse the new baby and the mother back to normal. Here her duties vary from bathing the new baby and the mother, to cooking and attending to other domestic chores. Before leaving for such a long period, she would hand over her shop to one of her sons ${ }^{\mathrm{xxi}}$ to run as the her family's survival rests on the income it generates. Besides, the MC loan and its interest must be paid on time.

On Sundays, she begins the day with adoration at the church and later family luncheon. She personally supervises all houseworks and take stock of her household needs. This is often followed by a visit to the neighbours, extended family members or friends. First Sundays of every month is designated for community meetings and gatherings ${ }^{\mathrm{xxii}}$. She is compelled to be present because she holds an official position in this union. Part of her responsibilities for her community include - marriage counselling, presence at community social functions like dances, marriages, funerals, political gathering, community development projects and general women's welfare. Her role as an elder in the church (and community) and an official of the women's association represent huge responsibilities and expectations. Like her role in the family, the decisions she reached are more likely to be presented to male leaders of the community or church. Although her utilization of MC has kept her micro enterprise afloat, it does not change her position as a wife and a woman. She maintains: A woman is still a woman, regardless of her wealth or education, she must listen to her husband and his family. A woman's husband or his family is like a crown on her head.

The stories presented above have been shaped by various factors, such as location, age and the number of children and status (wife and widow) in their families. Obviously, CP11 and MCP14 have overwhelming differences. Even though both are market women, their activities and responsibilities to their families differs. One aspect of such differences is in the number of children ${ }^{\text {xxii }}$ and the role these offspring would play as they mature.

The analysis presented above indicates that irrespective of differences, market women are economically active and they invest both energy, time and money in their families and community. In other words, the family and community are the centre of their existence and commitment. Overall, the information shows these women have 'no leave and no transfer' in the affairs of their families and communities. In many ways the micro credit scheme has added or increased their responsibilities as a result of loan repayment the borrowing costs.

The information also shows that while market women are actively engrossed in economic activities, they are juggling domestic duties, child rearing, communal responsibility and other social issues peculiar to their societies. The illustration of participants' daily lives and their account, tales or voices as narrated here aimed to support the argument that the micro credit scheme promotes economic participation. However, in return, it increases women's workload. What is more, there is no absolute guarantee that economic participation of 
women with the assistance of $\mathrm{MC}$ will radically transform old societal norms and traditions. In fact, the level of gender equality or economic empowerment through MC is overestimated. Bateman and Chang in their 2009 work, echoed a similar understanding of micro credit/finance. They argued,

Experience shows that microfinance actually encourages informality, as it is directed to unproductive economic activities, and discourages enterprises with growth potential, since microfinance institutions give priority to short-term loans and emphasise quick repayment rather than financing long-term productive enterprises (Bateman and Chang 2009).

\section{Conclusion}

Although credit is an instrument for investment and growth, the task of repayment and the payment of borrowing costs may present a bigger dilemma if recipients fail to meet the deadlines. By merely addressing the financial woes of women, and leaving behind their traditional roles is equivalent to creating additional predicament, but one with 'no name' (see Friedan 1983). The data from the field is explicit on women's role in Nigeria as most respondents depict it as 'natural' or 'a divine inclination'. The data here show that (market) woman shoulder critical life-sustaining responsibilities without which men and the entire family may not survive much less enjoy high levels of productivity. Generally, women's huge contribution to their family's survival and sustainability is primarily attested by the swift remarriage by most widowers. Respondents in this study combine this tedious home keeping with economic activities.

According to the literatures, the contribution of micro credit (Micro Financing) schemes to women's empowerment varies from woman to woman and from region to region. For example, in places like Bangladesh, India, and Niger Republic, the scheme has enhanced women's mobility and access to wider society-an exclusive right of men in those societies. In other countries, the scheme promotes economic participation and sometimes a limited economic empowerment. However, the question that remains unanswered is: At what cost is the utilization of $\mathrm{MC}$ in terms of workload, commitment, health issues, gender-equality and indebtedness?

It is very unclear the nature of empowerment the market women have gained through the MC. This is because prior to MC, market women in both Oyo and Imo states have a high level of mobility. Most are into trading, and shoulder family responsibilities. Therefore, the nature of empowerment that MC provides for the respondents in this study is not obvious, but rather it increases their family responsibilities. Obviously, the scheme may have succeeded in pushing thousands of women into the micro or small entrepreneur, but it has likewise created larger problems. Because, as many of these women make extra cash, their financial commitment and responsibilities to their families increase while decreasing those of their spouses and government. Data collected for this study illustrated that micro credit loans do not automatically change gender roles nor re-position society's ideologies of maleness and femaleness. This study has shown enough evidence that micro credit/finance scheme will not be enough to overcome all gender issues or trail the framework presented in Fig. 1., Perhaps a more realistic outline is presented in Fig. 2.

It is, therefore, necessary for the state to promote policies based on a bottom up approach rather than top down approach. The fact that $\mathrm{MC}$ worked in some countries does not automatically mean that it will work in Nigeria. Furthermore, there is a need for a support system to help overcome the mindset on issues on gender categorization in the household. Likewise, a relatively longer repayment period and relatively lower interest rate for loans from $\mathrm{MC}$ is a must.

\section{References}

[1] Nabil. and C. Kerbage, women's entrepreneurship development initiatives in lebanon: micro-achievements and macro-gaps. Gender \& Development 20/1 (2012): 67-80.

[2] Achebe, things fall apart. (United Kingdom: William Heinemann Ltd, 1958).

[3] H. Afshar Women and Empowerment. Great Britain: (Antony Rowe Ltd, 1998)

[4] A. A. Aidoo, The African Women Today. Edited by Nnaemeka Obioma. (Trenton New Jersey: African World press, 1998).

[5] G. B. Ayittey, african unchained: the blueprint for africa's future. (USA: Palgrave Macmillan, 2005).

[6] E. Babbie, the practice of social research. (Australia: Wadsworth, 2010)

[7] J. Beoku-Betts, western perceptions of african women in the $19^{\text {th }}$ and early 20 th centuries. African Research Bulletin 5/4(1976): 86 $-114$.

[8] E. Boserup, women's role in economic development. (London: Allen and Unwin, 1970).

[9] A. Cornwall, readings in gender in africa. (Bloomington: Indiana University Press, 2005).

[10] Narayan. K. P. Raj. Rademacher, A. Schafft, and S. Koch-Schulte, voices of the poor: can anyone hear us? (Oxford: Oxford University Press, 2000).

[11] Elson. gender equity and efficiency in adjustment programmes. Edited by. H. Afshar, and C. Dennis, (London: Macmillan, 1992).

[12] A. Friedan, twenty years after the feminine mystique. (The New York Times, February 27, 1983).

[13] G. Clifford. thick descriptors: toward an interpretive theory of culture. (New York: Basic Books, 1973).

[14] N. Kabeer, is micro-finance a 'magic bullet' for women's empowerment? analysis of findings from south asia. (Economic and Political Weekly, October 29, 2005.

[15] K. Uma and M. Martin. development theory and practise: critical perspectives. (London: Palgrave, 2002).

[16] H. Mahbub ul, human development report 2002: deepening democracy in a fragmented world. UNDP. http://hdr.undp.org/reports/global/2002/en/ (assessed on June 12, 2013) 
[17] M. Melrose, labour pains: some considerations on the difficulties of researching juvenile prostitution”. Research Methodology 5/4 (2002): 343-353.

[18] M. Molyneux, mobilisation without emancipation? women's interests, states and revolution in Nicaragua. Feminist Studies 11/2 (1985): 227-554.

[19] N. Nkoli. perception of womanhood in nigeria and the challenge of development in feminist knowledge/identities". Culture \& Religion 2004. http://www.gwsafrica.org/knowledge/nkoli.htm October 122013.

[20] P.K. Nwanesi in pursue of women's economic empowerment via micro-credit scheme. (USA: VDM Verlag De Muller, 2008).

[21] O. Olusegun. and M. Akin. elements of development. (Abeokuta ALF Publications, 1991).

[22] J. Pilcher, and I. Whelehan. fifty key concepts in gender studies. (London: Sage Publications Ltd, 2004).

[23] S. Razavi and C. Miller, "from wid to gad: conceptual shifts in the women and development discourse". Occasional Paper 1, February 11 2012. <http://www.unrisd.org/unrisd/website/document.nsf/ (assessed on 12 April 2014)

[24] H. Roxin, B. Heidi, P. J. Koller, J. Lawonn, P. Nahida. J. Schappert, economic empowerment of women through micro credit: the case of the micro-finance investment and technical assistance facility. (Freetown/Berlin: SLE Pubilcation Series - S240, 2010).

[25] K. Sen, A. Development as Freedom. (New York: Knopf, 1999).

[26] S. Michael. "Advancing a Global Women's Economic Empowerment Movement through Microfinance, Entrepreneurial Culture, Economic Freedom". February 11 2013. <http://www.flowidealism.org/Downloads/WEE Overview.pdfs

[27] C. M. Snyder and M. Tadesse, african women and development: a history. (Johannesburg: Witwatersrand University Press, 1995).

[28] UN Habitat. progress report on removing discrimination against women in respect of property and inheritance rights. (Nairobi: United Nations Centre for Human Settlements, 2006).

[29] UNCDF. microfinance and the millennium development goals: a reader's guide to the millennium project reports and other un documents. <http://www.yearofmicrocredit.org/docs/mdgdoc_MN.pdf> October 122013

[30] W. L. Wallace,. sociological theory. (New Brunswick: Aldine Transaction, 2008).

[31] C. Wichterich, the globalized woman: reports from a future of inequality. (Australia: Spinifex Press, 2000).

[32] S. Wolfgang, the development dictionary: a guide to knowledge as power. (Johannesburg: Witwatersrand University Press, 1992).

[33] M. Yunus. banker to the poor: micro-lending and the battle against world poverty. (US: Public Affairs, 2003).

\section{Endnotes}

${ }^{\mathrm{i}}$ One of the most prestigious awards in the world, Nobel Peace Prize was given to Muhammad Yunus for his pioneering role in the development of the micro-credit sector.

ii This is because empowerment is about people -both women and men- taking control over their lives: setting their own agendas, gaining skills, building self-confidence, solving problems and developing self-reliance (see Molyneux 1985).

iii Conceivably, it is justifiable to say; the process of "development in the developing countries has by and large, marginalized women and deprived most of them both socioeconomic resources and authority within the household, without lightening the heavy burden of their so-called 'traditional roles (Afshar 1991, 115)".

iv Some researchers have argued that the 'neck of the family' is more powerful than the 'head of the family'. That argument is partially outside the scope of this present article.

v There are many others which capital base are from family members or children.

vi This enterprises nature of women from these two ethnic groups in Nigeria is an important Ingredient for marriage and motherhood.

vii It is important to stress that these approaches represented a unique and major steps towards reducing poverty and upholds gender equality especially for women in the developing countries.

${ }_{\text {viii }}$ But there is need to bear in mind that notion of empowerment differs and maybe interpreted based on individual or group's perception

ix This is a common prevalence in many developing countries with strong ties with IMF/World Bank economic policies. Nigeria for example, witnessed dramatic increase in women's economic activities as a result of the introduction of Structural Adjustment Programs in the 1980s. This equally increases women (especially mothers) economic contributions to their family.

${ }^{\mathrm{x}}$ The Research participants in this study are mainly market or rural women. To ensure confidentiality and identity of each participant has been tagged (for example, MCP, $\mathrm{CP} 1, \mathrm{CP} 12$ etc.). The $\mathrm{MC}$ in the respondents' initials indicates that they are micro credit participants.

${ }^{x i}$ Idle house-wife

xii It is common to see or hear (observed during my fieldwork) rural and market women singing-out or tuning out song after song in the middle of a hot day, and a tedious job either in the farm, home or market place.

xiii The other way is through sustaining the subsistence farming or even practising both.

xiv Mini transport buses

${ }^{x v}$ This respondent has a vegetable garden which she managed with her mother-in-law, but grows only few vegetables mainly for home consumption and sells small amount to neighbors only.

${ }^{x v i}$ Nigerian families (especially married couples) would never eat their dinner outside their homes, unless eating at a family friend or member's home, or on a journey.

xvii The respondent and her family live in a two bedroom flat, but share kitchen, tap and bathroom/toilet with three other families.

xviii Owerri is the capital of Imo state. Imo is located in the Southeast central of Nigeria.

xix These duties used to be performed entirely by her when her children were still young.

${ }^{x x}$ When I interviewed her, her major headache was the fact that two of daughters are not yet married. She argued that they are of marriage age and yet, suitors have not been making enquiries. According to her, "among the Ibos, the beauty of a woman is her husband".

${ }_{x \times i}$ Her first daughter is already married with two children and lives in Lagos.

xxii At the time of this interview, she is Vice-president of her community's "Women's Union"

xxiii Customarily, the rationale for large families in Nigeria is first and foremost for economic benefits families hope to harness in the future from them. 